CZASOPISMO INŻYNIERII LĄDOWEJ, ŚRODOWISKA I ARCHITEKTURY JOURNAL OF CIVIL ENGINEERING, ENVIRONMENT AND ARCHITECTURE JCEEA, t. XXXIII, z. 63 (1/II/16), styczeń-marzec 2016, s. 383-392

Piotr ZIELIŃSKI ${ }^{1}$

\title{
PROBLEMY OCENY WŁASNOŚCI MIESZANEK MINERALNO-CEMENTOWO-EMULSYJNYCH (MCE)
}

\begin{abstract}
Podbudowy z mieszanek MCE są podstawowym rodzajem technologii recyklingu nawierzchni w Polsce, wykonywanym już od około 20 lat. Dotychczas stosowany sposób oceny własności tych mieszanek jest zdaniem autora niewystarczający gdyż wykonywany jest na próbkach przygotowywanych w sposób ściśle kontrolowany. Cechy ich są w tym przypadku znacznie korzystniejsze od rzeczywistych, określonych na próbkach pobranych z wykonanej na budowie warstwy. W niniejszej publikacji przedstawiono wyniki badań wpływu metody zagęszczenia oraz wielkości próbek na podstawowe własności mieszanek MCE takie jak: zawartość wolnych przestrzeni w warstwie, moduł sztywności sprężystej (ITSM) i wytrzymałość na rozciąganie pośrednie (ITS). Analiza wyników pozwoliła na stwierdzenie, że własności próbek wykonywanych w ramach recepty laboratoryjnej są bardziej korzystne niż tych przygotowanych $\mathrm{z}$ mieszanki wymieszanej na budowie i zagęszczonej w laboratorium, natomiast najmniej korzystne właściwości posiadają próbki pobrane metodą odwiertów ze stwardniałej warstwy: charakteryzują się one największą porowatością, najmniejszą wytrzymałością na rozciąganie pośrednie i najmniejszym modułem sztywności sprężystej oraz dodatkowo wykazują największe rozrzuty wyników. Dla poprawnej oceny trwałości konstrukcji nawierzchni z podbudową z MCE, powinniśmy oceniać własności tej mieszanki określane na próbkach z odwiertów lub ewentualnie zmienić metodę laboratoryjnego przygotowywania próbek w taki sposób aby lepiej oddawała stan rzeczywisty.
\end{abstract}

Słowa kluczowe: mieszanka MCE, zawartość wolnej przestrzeni, moduł sztywności sprężystej (ITSM), wytrzymałość na rozciąganie pośrednie (ITS), analiza istotności różnic

\section{Wprowadzenie}

Analizując światowe trendy w zakresie technologii stosowanych w przebudowie dróg można zaobserwować coraz większy nacisk na powtórne wykorzystanie zasobów ulokowanych w istniejącej infrastrukturze drogowej przy jednoczesnej tendencji wydłużania okresów eksploatacji konstrukcji nawierzchni, czego przykładem są prace amerykańskie w ramach programu SHRP2 [1]. W zakresie recyklingu nawierzchni główne kierunki zainteresowań obejmują

\footnotetext{
${ }^{1}$ Piotr Zieliński, Politechnika Krakowska, Katedra Budowy Dróg i Inżynierii Ruchu, ul. Warszawska 24, 31-155 Kraków; tel. 126282323; pzielin@pk.edu.pl
} 
wykorzystanie granulatu asfaltowego w produkcji mieszanek mineralnoasfaltowych w technologii na gorąco (np. prace amerykańskie [2], europejskie [3] czy australijskie [4]) oraz recykling na zimno istniejących konstrukcji nawierzchni z użyciem emulsji lub asfaltu spienionego, gdzie prace są kontynuowane w wielu krajach np. Wielka Brytania [5], Niemcy [6] czy Australia [7].

Niniejsza publikacja dotyczy podstawowej technologii recyklingu na zimno stosowanej w Polsce tj. mieszanek MCE. Podbudowy z mieszanek mineralno-cementowo-emulsyjnych są wykonywane w Polsce od około 20 lat, pierwsze wytyczne opracowano już w 1997 r., a następnie zmodyfikowano w 1999 r. [8], jednak aplikacje nie zawsze kończyły się powodzeniem. Wynikało to w dużej mierze z nieadekwatnych do warunków pracy warstwy metod badawczych a także trudności w ocenie rzeczywistych własności tych mieszanek, które charakteryzują się znacznie większą zmiennością cech w stosunku do mieszanek mineralno-asfaltowych. Powyższe przyczyny były powodem weryfikacji wymagań dla mieszanek MCE (wykonanych na Politechnice Gdańskiej), która doprowadziła do opracowania nowej instrukcji projektowania i wbudowywania mieszanek MCE [9]. W ww. instrukcji zamiast stabilności i odkształcenia próbek MCE wprowadzono kryteria oparte na badaniu modułu sztywności, wytrzymałości na rozciąganie pośrednie oraz odporności próbek na działanie wody, niemniej odbiór robót odbywa się dalej na podstawie oceny próbek pobranych z wymieszanej luźnej mieszanki przed jej zagęszczeniem w warstwie, które są następnie zagęszczane w laboratorium. Problemem jest tutaj sposób zagęszczania próbek badawczych, który daje rozbieżne wyniki w stosunku do próbek odwierconych z wykonanej warstwy MCE.

W niniejszej publikacji przedstawiono wyniki badań wpływu metody zagęszczenia oraz wielkości próbek na podstawowe własności mieszanek MCE takie jak: zawartość wolnych przestrzeni w warstwie, moduł sztywności sprężystej (ITSM) i wytrzymałość na rozciąganie pośrednie (ITS).

\section{Program badań}

Badaniom poddano zarówno mieszanki MCE pobrane $\mathrm{z}$ wykonanej podbudowy drogi powiatowej w Grojcu jak również przygotowane w laboratorium Politechniki Krakowskiej w ramach prac $[10,11]$. Mieszanki MCE pobrane na budowie dowieziono do laboratorium i zagęszczono w formach o średnicy 101,6 mm z wykorzystaniem ubijaka Marshalla. Dodatkowo ze stwardniałej podbudowy pobrano próbki o średnicy $150 \mathrm{~mm}$ metodą odwiertów. Dla mieszanek przygotowywanych w laboratorium wykonano próbki o średnicach 101,6 mm i $150 \mathrm{~mm}$ zagęszczane w prasie statycznej jak również z wykorzystaniem ubijaka Marshalla (średnica 101,6 mm). Badania w zależności od pochodzenia próbek obejmowały:

- określenie gęstości objętościowej metodą hydrostatyczną wg [12],

- określenie gęstości mieszanki MCE w piknometrze wg [13]doskonała przyczepność do różnych materiałów, 
- obliczenie zawartości wolnych przestrzeni w próbkach MCE wg [14],

- badania modułu sztywności (ITSM) w aparacie NAT wg metody IT-CY $\mathrm{w}$ temperaturze $+5^{\circ} \mathrm{C}$ wg [15] (dla recepty MCE1 wykonano również badania w temperaturze $+20^{\circ} \mathrm{C}$ ),

- badania wytrzymałości na rozciąganie pośrednie (ITS) w prasie Marshalla w temperaturze $+5^{\circ} \mathrm{C}$ wg [16].

Badania ITSM i ITS dla wszystkich mieszanek wykonano dla próbek sezonowanych w warunkach suchych, a dla mieszanki z drogi powiatowej w Grojcu badania te przeprowadzono dodatkowo również dla próbek sezonowanych w warunkach mokrych, wg procedur przewidzianych w nowych polskich wytycznych [9]. Badania wytrzymałościowe były prowadzone dla próbek po 7 i 28 dniach od zagęszczenia, liczebność próbek w poszczególnych seriach wynosiła od 3 (dla próbek badanych po 7 dniach) do 9 (dla próbek badanych po 28 dniach, całkowitą liczebność próbek do poszczególnych badań dla każdej analizowanej mieszanki zestawiono w tabeli 1.

Wyniki przedmiotowych badań dla poszczególnych serii próbek poddano analizie statystycznej obejmującej wyznaczenie podstawowych charakterystyk takich jak: wartość średnia, odchylenie standardowe czy wskaźnik zmienności a następnie wykonano testy istotności różnic wartości średniej dla próbek zagęszczanych wg podanych wyżej metod (testy wielokrotnych porównań wg procedury Fishera LSD w programie Statgraphics dla poziomu ufności 95\% [17]).

Tabela 1. Program badań mieszanek MCE

Table 1. Program of testing of MCE mixtures

\begin{tabular}{|c|c|c|c|c|c|c|}
\hline \multirow{3}{*}{ Lp. } & \multirow{3}{*}{ Pochodzenie próbki } & \multicolumn{5}{|c|}{ Badana cecha (liczba próbek) } \\
\hline & & \multirow{2}{*}{\begin{tabular}{|c|} 
Próżnia \\
{$[\%]$}
\end{tabular}} & \multicolumn{2}{|c|}{ ITSM [MPa] } & \multicolumn{2}{|c|}{ ITS [MPa] } \\
\hline & & & Na mokro & Na sucho & Na mokro & Na sucho \\
\hline 1 & Mieszanka laboratoryjna wg [11] & 12 & - & 12 & - & 18 \\
\hline 2 & $\begin{array}{l}\text { Mieszanka pobrana z DP w Groj- } \\
\text { cu [12] }\end{array}$ & 15 & 4 & 5 & 4 & 5 \\
\hline 3 & Odwierty z DP w Grojcu [12] & 10 & - & 10 & - & - \\
\hline 4 & $\begin{array}{c}\text { Mieszanka laboratoryjna wg [12] } \\
\text { ze składników pobranych z DP } \\
\text { w Grojcu }\end{array}$ & 15 & 4 & 5 & 4 & 5 \\
\hline & Razem & 52 & 8 & 32 & 8 & 28 \\
\hline
\end{tabular}

\section{Wyniki badań}

\subsection{Badania mieszanki laboratoryjnej wg [11]}

W wyniku optymalizacji przeprowadzonej w laboratorium przyjęto następujący skład mieszanki dla MCE-1:

- destrukt asfaltowy z frezowania nawierzchni - $72.1 \%$,

- kruszywo doziarniające 0/4 mm - 22.1\%, 
- emulsja asfaltowa C60 B5 R - 3.9\%,

- cement CEM I $32.5 \mathrm{R}-1.9 \%$.

Następnym krokiem było przygotowanie próbek badawczych, wykorzystano 2 metody zagęszczania t $\mathrm{j}$.:

- próbki o średnicy $150 \mathrm{~mm}$ zagęszczane w prasie pod obciążeniem $49 \mathrm{kN}$ w cyklach dwuminutowych z częściowym odciążaniem i ponownym dociążaniem, zgodnie z wytycznymi niemieckimi [9] (seria N),

- próbki o średnicy $101.6 \mathrm{~mm}$ zagęszczane w prasie statycznej pod obciążeniem $100 \mathrm{kN}$ w czasie 5 minut, zgodnie ze starymi polskimi wytycznymi [8] (seria P).

Na przygotowanych w taki sposób próbkach określono zawartość wolnych przestrzeni, moduł sztywności sprężystej w temperaturze $+5^{\circ} \mathrm{C} \mathrm{i}+20^{\circ} \mathrm{C}$ oraz wytrzymałość na rozciąganie pośrednie $\mathrm{w}$ temperaturze $+5^{\circ} \mathrm{C}$ (zarówno badanie ITSM jak i ITS przeprowadzono na próbkach po 7 i 28 dniach pielęgnacji). Wyniki przedmiotowych badań wraz $\mathrm{z}$ analizą istotności różnic pomiędzy próbkami zagęszczanymi wg podanych wyżej metod zestawiono w tabeli 2, na rysunku 2 zestawiono wyniki badań ITSM w zależności od temperatury i czasu sezonowania poszczególnych serii próbek.

Przedstawione wyniki potwierdzają bardzo istotny wpływ stosowanej metody zagęszczania próbek MCE na ich podstawowe właściwości fizyczne i wytrzymałościowe; próbki zagęszczane statycznie wg starych polskich wytycznych miały prawie dwukrotnie mniejszą zawartość wolnych przestrzeni, wykazywały dwukrotnie wyższą sztywność oraz około trzykrotnie wyższą wytrzymałość na rozciąganie pośrednie od próbek zagęszczanych wg metody niemieckiej. Dodatkowo dla porównania przedstawionych w tabeli 1 wyników próbek przygotowywanych w laboratorium pobrano 5 próbek z wykonanej podbudowy MCE, na któ-

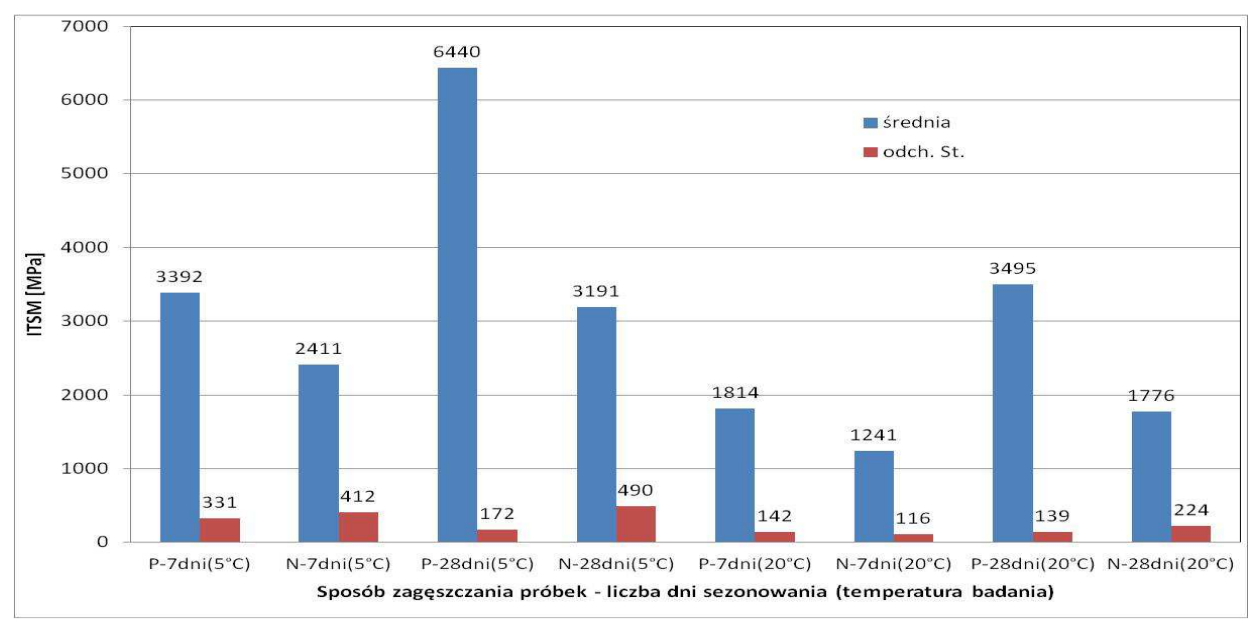

Rys.1. Wyniki badań modułu sztywności sprężystej próbek wg recepty MCE-1

Fig. 1. The test results of the stiffness modulus of samples acc. to the recipe MCE-1 
Tabela 2. Wyniki badań próbek mieszanki laboratoryjnej w temperaturze $+5^{\circ} \mathrm{C}$ (MCE1), wg [11]

Table 2. The test results of laboratory mix samples at the temperature $+5^{\circ} \mathrm{C}$ (MCE1), acc. to [11]

\begin{tabular}{|c|c|c|c|c|c|c|}
\hline \multirow{3}{*}{ Lp. } & \multirow{3}{*}{ Właściwość } & \multicolumn{5}{|c|}{ Badana cecha dla próbek o średnicy 100/ $\underline{150}$ [mm] } \\
\hline & & \multirow{2}{*}{$\begin{array}{c}\text { Próżnia } \\
{[\%]}\end{array}$} & \multicolumn{2}{|c|}{ ITSM [MPa] } & \multicolumn{2}{|c|}{ ITS [MPa] } \\
\hline & & & $7 \mathrm{dni}$ & 28 dni & 7 dni & 28 dni \\
\hline 1 & Wartość średnia & $7.0 / \underline{13.2}$ & $3392 / \underline{2411}$ & $6440 / \underline{3191}$ & $0.687 / \underline{0.239}$ & $1,322 / \underline{0,467}$ \\
\hline 2 & Odchylenie standardowe & $0.17 / \underline{0.76}$ & $331 / \underline{412}$ & $172 / \underline{490}$ & $0.087 / \underline{0.012}$ & $0.151 / \underline{0.105}$ \\
\hline 3 & Wskaźnik zmienności [\%] & $2.5 / \underline{5.7}$ & $9.8 / 17.1$ & $2.7 / 15.3$ & $12.6 / 4.8$ & $11.4 / \underline{22.5}$ \\
\hline 4 & $\begin{array}{l}\text { Różnica dla próbek } \\
\text { o średnicy } 100 \mathrm{~mm} \\
\text { i } 150 \mathrm{~mm} \\
\end{array}$ & $6.2 *$ & $981^{*}$ & $3249 *$ & $0.448^{*}$ & $0.855^{*}$ \\
\hline 5 & Granica istotności różnic & 2.1 & 646 & 456 & 0.186 & 0.131 \\
\hline
\end{tabular}

* stwierdzono statystycznie istotną różnicę badanych właściwości

rych przeprowadzono badanie ITS. Wyniki uzyskane na odwiertach (średni ITS $=0.424 \mathrm{MPa}$ ) były zbliżone do osiągniętych na próbkach zagęszczanych wg metody niemieckiej (średni ITS $=0.467 \mathrm{MPa}$ ) co potwierdza spostrzeżenia pracy [18], że metodą dającą lepsze odwzorowanie rzeczywistych warunków zagęszczenia próbek laboratoryjnych jest metoda niemiecka.

\subsection{Badania mieszanki z DP w Grojcu wg [12]}

Do badań przygotowano 3 rodzaje próbek MCE-2 z wykorzystaniem materiałów pobranych przy przebudowie DP w Grojcu tj.:

- z mieszanki pobranej za recyklerem przygotowano próbki o średnicy $101.6 \mathrm{~mm}$ zagęszczone w ubijaku Marshalla wg nowych polskich wytycznych [9] (seria R),

- ze stwardniałej podbudowy wycięto wiertnicą próbki o średnicy $150 \mathrm{~mm}$ (seria $\mathbf{O}$ ),

- $\mathrm{z}$ destruktu pobranego po frezowaniu warstw asfaltowych (67.6\%), kruszywa doziarniającego 0/4 mm (26.5\%), emulsji asfaltowej (3.5\%) i cementu (2.4\%) przygotowano w laboratorium próbki zagęszczane w ubijaku Marshalla wg nowych polskich wytycznych [9] (seria L).

Na wszystkich próbkach określono zawartość wolnych przestrzeni, następnie przeprowadzono następujące badania:

- seria R i L - po 3 próbki z każdej serii podano badaniu ITS po 7 dniach sezonowania, następnie próbki podzielono na serię mokrą suchą (zgodnie z wytycznymi [9]), po 28 dniach sezonowania na obu seriach próbek wykonano badanie modułu sztywności wg procedury ITSM w NAT $\mathrm{w}+5^{\circ} \mathrm{C}$ oraz $\mathrm{w}$ tej samej temperaturze badanie ITS, co pozwoliło określić wpływ sezonowania próbek w wodzie na spadek modułu sztywności i wytrzymałość na rozciąganie pośrednie próbek MCE.

- seria $\mathrm{O}$ - dla 10 próbek uzyskanych z odwiertów wykonano badania modułu sztywności sprężystej (ITSM) w temperaturze $+5^{\circ} \mathrm{C}$. 
Wyniki badań dla mieszanki MCE-2 przedstawiono na rys. 2 (zawartość wolnych przestrzeni), rys. 3. (ITSM) oraz rys. 4 (ITS). Ponadto wykonano analizę istotności różnic dla podanych powyżej wyników ze względu na metodę przygotowania próbki (serie: $\mathrm{R}, \mathrm{O}$ i L) oraz sposób jej sezonowania (na sucho lub na mokro), wyniki tych analiz zestawiono w tablicy 3 .

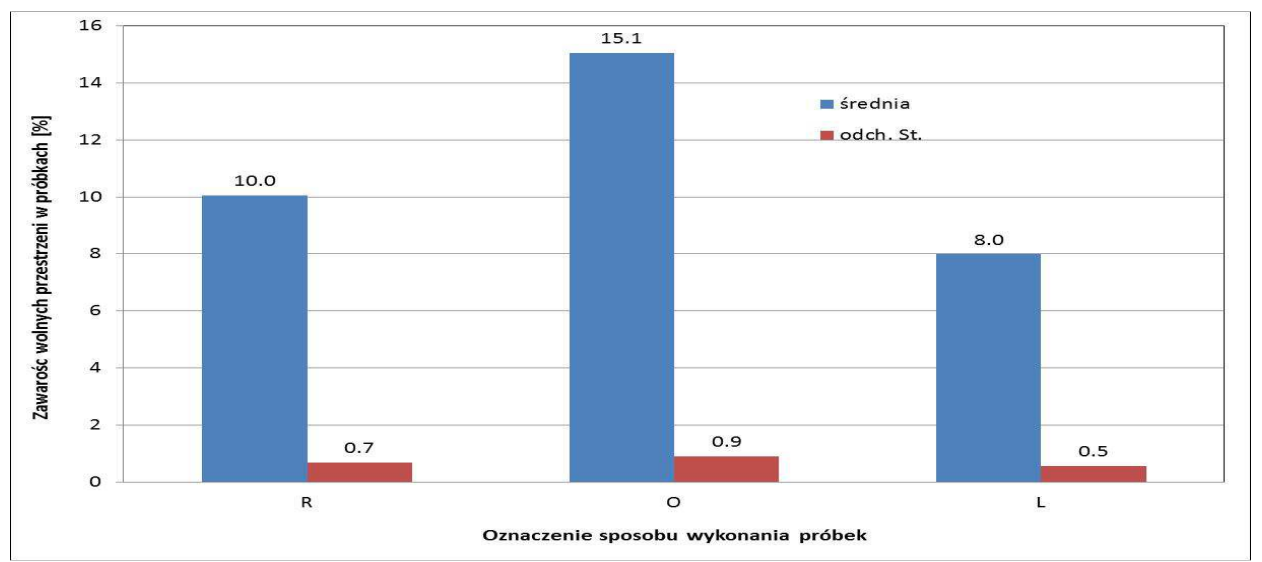

Rys. 2. Wyniki badań zawartości wolnych przestrzeni dla próbek z różnych serii MCE-2

Fig. 2. The test results of air voids for a series of samples of different MCE-2

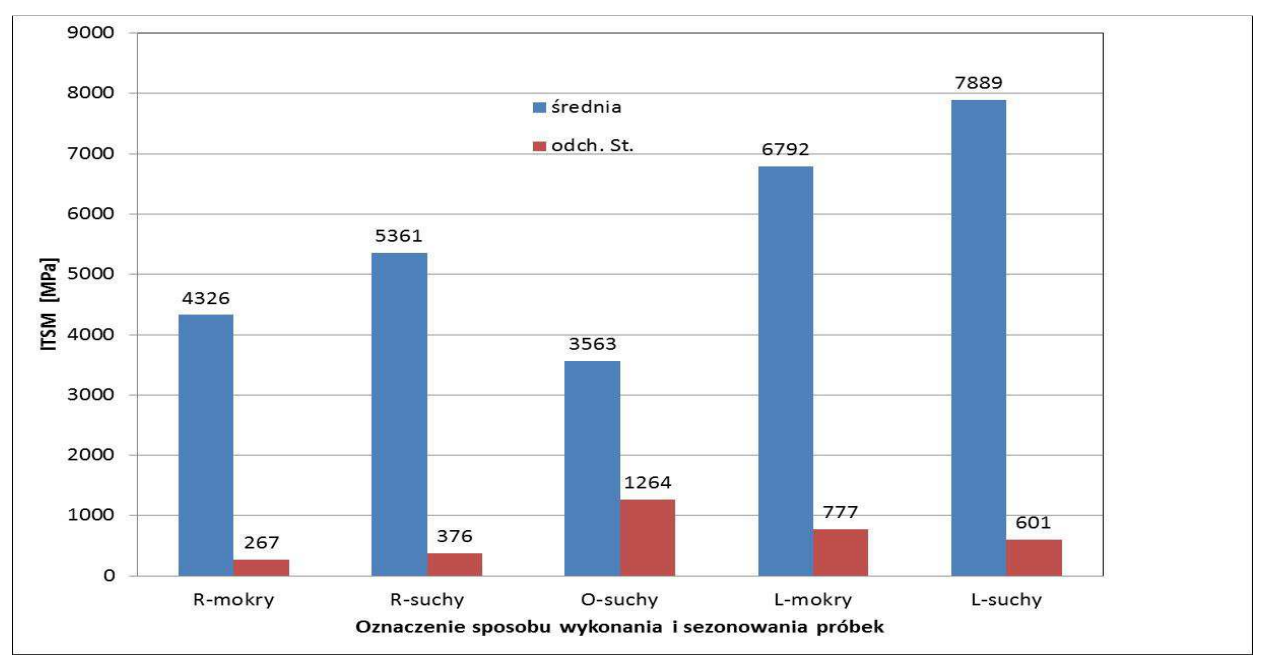

Rys. 3. Wyniki badań modułu sztywności sprężystej dla próbek MCE-2 $\mathrm{w}$ temperaturze $+5^{\circ} \mathrm{C}$

Fig. 3. The test results of the stiffness modulus for the samples MCE-2 at the temperature $+5^{\circ} \mathrm{C}$ 
Tabela 3. Wyniki analiz istotności różnic dla wartości średnich parametrów próbek mieszanki MCE, wg [12]

Table 3. The results of the significance of differences in mean values parameters of MCE mix, acc. to [12]

\begin{tabular}{|c|c|c|c|c|c|c|}
\hline \multirow{2}{*}{ Lp. } & \multirow{2}{*}{$\begin{array}{c}\text { Analizowane } \\
\text { serie }\end{array}$} & \multirow{2}{*}{ Próżnia [\%] } & \multicolumn{2}{|c|}{ Różnica / granica istotności różnic (95\%) } \\
\cline { 5 - 7 } & & mokre & suche & mokre & ITS [MPa] \\
\hline 1 & $\mathrm{~L}-\mathrm{R}$ & $2,0^{*} / 0,5$ & $2466^{*} / 1308$ & $2528^{*} / 1170$ & $0,203^{*} / 0,073$ & $0,072 * / 0,066$ \\
\hline 2 & $\mathrm{~L}-\mathrm{O}$ & $7,1^{*} / 0,6$ & Nie badano & $4326^{*} / 1014$ & Nie badano & Nie badano \\
\hline 3 & $\mathrm{R}-\mathrm{O}$ & $2,0^{*} / 0,6$ & Nie badano & $1797 * / 1024$ & Nie badano & Nie badano \\
\hline
\end{tabular}

* stwierdzono statystycznie istotną różnicę badanych właściwości

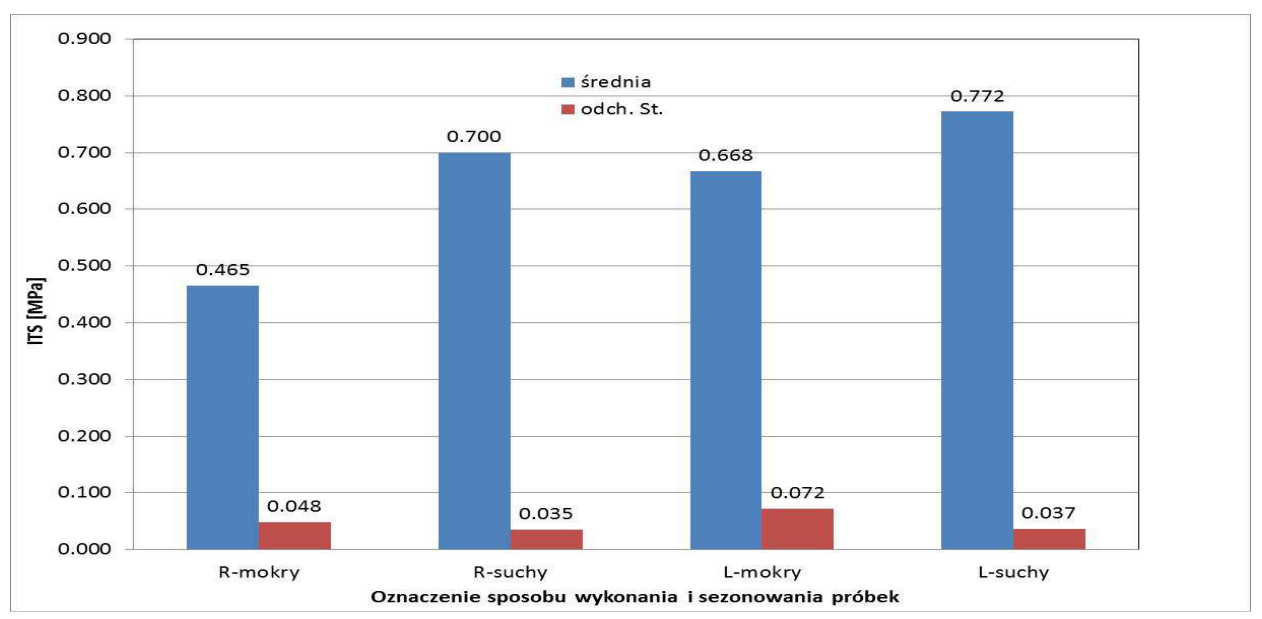

Rys. 4. Wyniki badań ITS dla próbek MCE-2 w temperaturze $+5^{\circ} \mathrm{C}$

Fig. 4. The test results of ITS for the samples MCE-2 at the temperature $+5^{\circ} \mathrm{C}$

Przedstawione powyżej wyniki wskazują na istotnie lepsze własności próbek mieszanek MCE przygotowywanych $\mathrm{w}$ całości w laboratorium (seria L) $\mathrm{w}$ stosunku do tych pobranych $\mathrm{z}$ budowy i zagęszczanych w laboratorium (seria $\mathrm{R})$, które z kolei są istotnie lepsze w stosunku do próbek pobranych ze stwardniałej warstwy podbudowy (seria O). W stosunku do poszczególnych własności uzyskano następującą ocenę wartości średnich:

- zawartość wolnych przestrzeni w próbkach laboratoryjnych (seria L) jest o $2 \%$ mniejsza niż w serii $\mathrm{R}$ i aż o około $7 \%$ mniejsza niż w odwiertach (seria $\mathrm{O}$ ),

- moduł sztywności sprężystej badany w warunkach suchych w temperaturze $+5^{\circ} \mathrm{C}$ dla próbek serii L jest o około $50 \%$ wyższy w stosunku do serii $\mathrm{R}$ i ponad dwukrotnie wyższy w porównaniu do serii $\mathrm{O}$, ponadto próbki pobrane metodą odwiertów charakteryzowały się bardzo dużymi rozrzutami (wskaź- 
nik zmienności 35\%) podczas gdy w seria L i R wskaźnik zmienności wynosił około $5 \%$,

- stosunek modułu sztywności sprężystej badanego na mokro i na sucho dla próbek laboratoryjnych (seria L) był wyższy niż dla tych z mieszanki pobranej na budowie i zagęszczonej w laboratorium (seria R) i wynosił odpowiednio $86 \%$ i $81 \%$,

- wytrzymałość na rozciąganie pośrednie dla próbek serii L jest istotnie wyższa w stosunku do serii R, przy czym znacznie większą różnice odnotowano dla próbek badanych na mokro (około 44\%) niż dla próbek badanych na sucho (około 10\%), niemniej w obu przypadkach są to różnice statystycznie istotne,

- stosunek wytrzymałości na rozciąganie pośrednie badanej na mokro i na sucho dla próbek laboratoryjnych (seria L) był znacznie wyższy niż dla tych $\mathrm{z}$ mieszanki pobranej na budowie i zagęszczonej w laboratorium (seria R) i wynosił odpowiednio $86 \%$ i $66 \%$.

\section{Wnioski końcowe}

Przedstawione wyniki badań wskazują na problem istotnych różnic w zakresie podstawowych, wymaganych krajowymi przepisami [9] właściwości próbek mieszanek MCE takich jak: zawartość wolnych przestrzeni, moduł sztywności sprężystej (ITSM) oraz wytrzymałość na rozciąganie pośrednie (ITS) w zależności od sposobu przygotowania próbki (recepta laboratoryjna, mieszanka pobrana $\mathrm{z}$ budowy i zagęszczona w laboratorium, odwiert $\mathrm{z}$ wykonanej warstwy podbudowy).

W ramach badań mieszanki MCE-1 stwierdzono, że próbki laboratoryjne przygotowane zgodnie z przepisami niemieckimi charakteryzują się właściwościami zbliżonymi do właściwości rzeczywistej warstwy, badanej na odwiertach, podczas gdy sposób zagęszczania próbek obowiązujący w starych polskich wytycznych [8] daje wyniki zbyt optymistyczne, zawyżając sztywność i wytrzymałość na rozciąganie pośrednie oraz zaniżając zawartość wolnych przestrzeni w warstwie.

W ramach badań mieszanki MCE-2 przeprowadzonej zgodnie z nowymi wymaganiami krajowymi [9]stwierdzono, że rzeczywiste właściwości warstwy podbudowy z MCE badane na próbkach z odwiertów są istotnie gorsze od tych określonych $\mathrm{w}$ recepcie laboratoryjnej czy w ramach badań odbiorczych (próbki z mieszanki MCE pobranej na drodze i zagęszczonej w sposób znormalizowany w laboratorium). Ponadto właściwości warstwy podbudowy z MCE charakteryzują się znacznie większą niejednorodnością niż w przypadku próbek wykonywanych w ramach recepty czy badań odbiorczych.

Biorąc pod uwagę powyższe spostrzeżenia, jeżeli nie ulegnie zmianie metoda przygotowywania próbek w ramach recepty, przy projektowaniu konstrukcji nawierzchni z podbudową z MCE należy przewidzieć odpowiednie zapasy bezpieczeństwa dla przyjmowanych charakterystyk materiałowych tj. zawartości 
wolnych przestrzeni w warstwie, modułu sztywności czy wytrzymałości na rozciąganie pośrednie.

\section{Literatura}

[1] Jackson N., Mahoney J., Puccinelli J.: Using the Existing Pavement In Place and Achieving Long Life. SHRP 2 Renewal Project R23, TRB, USA 2012.

[2] Boriack P., Katicha S., Flintsch G., Tomlinson C.: Laboratory Evaluation of Asphalt Concrete Mixtures Containing High Contents of Reclaimed Asphalt Pavement (RAP) and Binder, Virginia Center for Transportation Innovation and Reseach, Charlottesville 2014.

[3] Kuttah D. at al: Production and processing of reclaimed asphalt - selected case studies, European Commision DG Reseach, 2012.

[4] Denneman E., Dias M., Malone S., Choi Y., Woodall E., Urquhart R.: Maximising the Re-use of Reclaimed Asphalt Pavement: Binder Blend Characterisation. Austroads Technical Raport, Sydney 2013.

[5] Merril D., Nunn M., Carswell I.: A guide to the use and specification of cold recycled materials for the maintenance of road pavements, TRL Report no 611, 2004.

[6] Merkblatt für Kaltrecycling in situ im Straßenoberbau“ Forschungsgesellschaft für Straßen- und Verkehrswesen Arbeitsgruppe Mineralstoffe im Straßenbau, Köln, 2005.

[7] Design and performance of foamed bitumen stabilised pavements: Progress report one, Austroads Technical Report, Sydney 2013.

[8] Zawadzki J., Matras J., Mechowski T., Sybilski D.: Warunki technicznych wykonania warstw podbudowy $\mathrm{z}$ mieszanki mineralno-cementowo emulsyjnej (MCE), IBDiM, Zeszyt 61, Warszawa 1999.

[9] Dołżycki B.: Instrukcja projektowania i wbudowywania mieszanek mineralnocementowo-emulsyjnych (MCE), Politechnika Gdańska, Gdańsk 2014.

[10] Dzieciuch D., Jarczyk P.: Badanie mieszanki MCE wg starych i nowych polskich warunków technicznych, praca dyplomowa inżynierska pod kierunkiem dr inż. Piotra Zielińskiego, Politechnika Krakowska, 2014.

[11] Gałecki K., Pękala M.: Badania mieszanek mineralno-cementowo-emulsyjnych, praca dyplomowa magisterska pod kierunkiem dr inż. Piotra Zielińskiego, Politechnika Krakowska, 2015.

[12] PN-EN 12697-5 Mieszanki mineralno-asfaltowe - Metody badań mieszanek mineralno-asfaltowych na gorąco - Część 5: Oznaczanie gęstości.

[13] PN-EN 12697-6 Mieszanki mineralno-asfaltowe - Metody badań mieszanek mineralno-asfaltowych na gorąco - Część 6: Oznaczanie gęstości objętościowej metodą hydrostatyczną.

[14] PN-EN 12697-8 Mieszanki mineralno-asfaltowe - Metody badań mieszanek mineralno-asfaltowych na gorąco - Część 8: Oznaczanie zawartości wolnej przestrzeni.

[15] PN-EN 12697-26 Mieszanki mineralno-asfaltowe - Metody badań mieszanek mineralno-asfaltowych na gorąco - Część 26: Sztywność.

[16] PN-EN 12697-23 Mieszanki mineralno-asfaltowe - Metody badania mieszanek mineralno-asfaltowych na gorąco - Część 23: Określanie pośredniej wytrzymałości na rozciąganie próbek asfaltowych. 
[17] Dobosz M. Wspomagana komputerowo statystyczna analiza wyników badań, Problemy współczesnej nauki, Teoria i zastosowania, STATYSTYKA, AOW EXIT, W-wa, 2001.

[18] Judycki J., Dołżycki B, Hunik K., Stienns M.: Weryfikacja zasad projektowania mieszanek mineralno-cementowo-emulsyjnych, Raport końcowy, Politechnika Gdańska, Gdańsk 2006.

\section{PROBLEMS OF MINERAL - CEMENT - EMULSION MIXTURES PROPERTY EVALUATION}

\section{S u m m a r y}

Mineral-cement-emulsion mixtures are the basic type of pavement recycling technology in Poland, implemented for about 20 years. Previously used method to assess the properties of these mixtures is in the author's opinion inadequate because it is performed on samples prepared in precisely controlled conditions. Their characteristics are more favorable than actual, specified on the samples taken from the layer constructed on the site. This publication presents the results of the effect of compaction method as well as the sample size on the basic properties of MCE mixture such as the content of air voids in the layer, the stiffness modulus (ITSM) and indirect tensile strength (ITS). Analysis of the results allowed to conclude that the properties of the samples taken in a laboratory recipe are more favorable than those prepared from an in-situ mixture compacted in the laboratory, while the least favorable properties have the samples drilled from the hardened layer: they are characterized by the highest porosity, the smallest indirect tensile strength and the lowest stiffness modulus, and additionally have the greatest dispersion of the results. Therefore, for a correct assessment of durability of the pavement structure with MCE base, we should evaluate properties of the mixture, determined on the samples from boreholes or change the method of sample preparation in laboratory in such a way that it could better express the actual situation.

Keywords: Mineral-cement-emulsion mixture (MCE), air voids content, stiffness modulus (ITSM), indirect tensile strength (ITS), the significance tests for differences.

Przestano do redakcji: 07.06.2016 $r$.

Przyjęto do druku: 30.06.2016 r.

DOI: $10.7862 / r b .2016 .98$ 